University of Nebraska - Lincoln

DigitalCommons@University of Nebraska - Lincoln

USDA National Wildlife Research Center - Staff Publications
U.S. Department of Agriculture: Animal and Plant Health Inspection Service

January 2003

\title{
An economic assessment of the potential for predator management to benefit Puerto Rican parrots
}

Richard M. Engeman

USDA-APHIS-Wildlife Services, s_r100@yahoo.com

Stephanie A. Shwiff

USDA/APHIS/WS National Wildlife Research Center, stephanie.a.shwiff@aphis.usda.gov

Felipe Cano

Caribbean National Forest Catalina Work Center

Bernice Constantin

USDA-APHIS-Wildlife Services

Follow this and additional works at: https://digitalcommons.unl.edu/icwdm_usdanwrc

Part of the Environmental Sciences Commons

Engeman, Richard M.; Shwiff, Stephanie A.; Cano, Felipe; and Constantin, Bernice, "An economic assessment of the potential for predator management to benefit Puerto Rican parrots" (2003). USDA National Wildlife Research Center - Staff Publications. 172.

https://digitalcommons.unl.edu/icwdm_usdanwrc/172

This Article is brought to you for free and open access by the U.S. Department of Agriculture: Animal and Plant Health Inspection Service at DigitalCommons@University of Nebraska - Lincoln. It has been accepted for inclusion in USDA National Wildlife Research Center - Staff Publications by an authorized administrator of DigitalCommons@University of Nebraska - Lincoln. 


\title{
An economic assessment of the potential for predator management to benefit Puerto Rican parrots
}

\author{
Richard M. Engeman ${ }^{\mathrm{a}, *}$, Stephanie A. Shwiff ${ }^{\mathrm{a}}$, Felipe Cano ${ }^{\mathrm{b}}$, \\ Bernice Constantin ${ }^{\mathrm{c}}$ \\ ${ }^{a}$ National Wildlife Research Center, 4101 LaPorte Ave, Fort Collins, CO 80521-2154, USA \\ ${ }^{\mathrm{b}}$ Caribbean National Forest Catalina Work Center, $191 \mathrm{Rd}$. Intersection 988, Km 4.5, Palmer, PR 00721, USA \\ ${ }^{\mathrm{c}}$ USDA/APHIS/WS, 2820 East University Ave., Gainesville, FL 32641, USA
}

Received 6 June 2002; received in revised form 19 May 2003; accepted 20 May 2003

\begin{abstract}
The Puerto Rican parrot is one of the ten most endangered birds in the world, with the only wild population comprised of 30-40 birds. Predation has been identified as one of the factors limiting Puerto Rican parrot productivity in the wild, and the loss of a very few birds can have a great impact on the species. Management of red-tailed hawks, and black rats, feral cats and Indian mongooses, as well as further management of pearly-eyed thrashers is potentially beneficial to the parrot population. Because funding for the recovery of this rare species is finite, an analytical examination of the economics of predator management as a species enhancement method can provide managers with a solid basis for justifying and implementing this management approach. We used a benefit-cost analysis (BCA) to examine the potential Pareto improvements of predator management for protecting Puerto Rican parrots. The median and minimum expenditures aimed at parrot reproduction for both captive and wild parrots from 1997 to 2001 were used to define monetary values for Puerto Rican parrots. Predator management costs were estimated from existing US Department of Agriculture/Wildlife Services (USDA/WS) contracts for similar work in Puerto Rico. We examined the benefit-cost ratios (BCRs) for predator management assuming one to five and ten parrots were saved by the efforts. Analyses were conducted separately for each predator species and all species combined. The primary analyses focused on the benefits and costs for predator management for the current wild parrot population in the Caribbean National Forest (CNF), but another set of analyses targeted the proposed Rio Abajo (RA) site for the establishment of a second wild population. This second set of analyses was more conservative than for the existing population because predator management costs were assumed to be higher. Even when using the minimum monetary valuation for Puerto Rican parrots, the prevention of a single mortality due to predation within the existing wild population results in monetary benefits slightly exceeding the combined costs for management of each predator species $(\mathrm{BCR}=1.01)$. If median parrot values are applied, then only one parrot saved every 2.6 years allows the combined predator management to be costeffective. If the year of maximal parrot values (averaged over captive and wild populations) is used, then only one parrot saved every 4.2 years makes application of all predator management methods cost-effective. Use of the single highest per-parrot value from among years and populations would result in the combined application of all forms of
\end{abstract}

\footnotetext{
* Corresponding author. Tel.: +1-970-266-6091; fax: +1-970-266-6089.

E-mail address: richard.m.engeman@aphis.usda.gov (R.M. Engeman).
} 
predator management being cost-effective if only one parrot is preserved from predation every 11.8 years. Assuming higher costs and minimum parrot values results in the combined application of predator management at the RA proposed population site to be cost-effective if 1.8 parrots/year are saved from predation. Use of median parrot value allows predation management to be cost-effective if one parrot is saved every 1.4 years. If actual costs for the RA site are the same as for the CNF, then the BCRs improve correspondingly. As more parrots are saved, the BCRs increase dramatically for each site.

Published by Elsevier B.V.

Keywords: Benefit-cost analysis; Benefit-cost ratios endangered species; Predation management

\section{Introduction}

The Puerto Rican parrot (Amazona vittata) is one of the ten most endangered birds in the world (US Fish and Wildlife Service, 1999). Currently, the only population of Puerto Rican parrots, comprised of 30-40 birds, is found in the Caribbean National Forest (CNF), Puerto Rico. Also, two captive breeding populations also are located in Puerto Rico. Predation is a critical threat to many endangered or even locally rare species (Hecht and Nickerson, 1999), and it has been identified as one of the factors limiting Puerto Rican parrot productivity in the wild (Lindsey et al., 1994; Snyder et al., 1987; US Fish and Wildlife Service, 1999). In today's environments, predation losses can have an increased deleterious impact due to the compounding effects of, among other things, habitat loss and altered predator communities (Reynolds and Tapper, 1996), both of which apply to Puerto Rico. Even the loss of a very few birds can have a great impact on a species as rare as the Puerto Rican parrot.

A logical consideration to aid in the conservation of Puerto Rican parrots would be to remove the predators geographically and temporally in position to pose a threat to members of the parrot population. Funding for the recovery of this rare species is finite and must be carefully applied to maximize the positive impact on the species. Thus, an analytical examination of the economics of a species enhancement method can provide managers with a solid basis for selecting and implementing methodologies aimed at conserving the species. Here, we use a benefit-cost analysis (BCA) to examine the potential Pareto improvements (e.g. Peterson and Randall, 1984) of pre- dator management for protecting Puerto Rican parrots.

\section{Methods}

The general approach for our economic evaluation of predator management for Puerto Rican parrot conservation was a four step procedure. The first step was to identify a monetary value for Puerto Rican parrots. The next step was to examine the various predators that could threaten wild Puerto Rican parrots through the year. The third step was to identify the costs for addressing the potential parrot predators. The final step was to apply this information in a BCA to identify the level at which predator management is costeffective.

Part of the Puerto Rican parrot recovery plan includes the establishment of a second wild population (Snyder et al., 1987; US Fish and Wildlife Service, 1982, 1999). A second population of Puerto Rican parrots is essential to recovery for the species by guarding against catastrophic natural events such as hurricanes (Vilella and Garcia, 1995), pathogen outbreaks (Warner, 1968; Scott, 1988; Wiley et al., 1991), and behavioral and genetic deterioration in captive populations (Franklin, 1980; Danielle and Murray, 1986; Lacey, 1987; Derrickson and Snyder, 1991; Wiley et al., 1991). The proposed location for a second population is in the karst forest region in the Rio Abajo (RA) Commonwealth Forest where the RA aviary is located (US Fish and Wildlife Service, 1999). Thus, our economic analysis considers not only the benefit-costs associated with the existing wild Puerto Rican parrot population in the CNF, 
but also for a potential population when established near the RA aviary.

\subsection{Puerto Rican parrot monetary values}

Determination of monetary values for rare species is not a straight-forward nor precise process. As an illustration, consider that values of endangered or threatened species have been deemed "incalculable" in US Supreme Court case law (Tennessee Valley Authority vs. Hill, 1978). Even so, conservative monetary values for rare species can be estimated through a variety of means (e.g. Engeman et al., in press). Values based on replacement costs derived from breeding project costs divided by the number of healthy individuals produced (e.g. Bodenchuk et al., 2002; Engeman et al., in press) provided concrete empirical data from which Puerto Rican parrot values could be ascribed. There are three sources for Puerto Rican parrots: the Luquillo aviary captive breeding operation at the CNF, the RA aviary captive breeding operation, and wild parrots in the CNF. Each parrot population is intensively managed and has an identifiable budget for its management, as well as data on the annual production of healthy fledglings. We assessed Puerto Rican parrot values by examining the budgets and parrot productivity from each of these sources for 5 years from 1997 through 2001. The combined average cost per individual produced across the three populations was calculated for each year by dividing the combined budget for the three populations by their combined production of healthy fledglings. We conducted economic analyses using the median individual production cost from the 5 years as the value assigned to Puerto Rican parrots, and we also conducted more conservative analyses using the minimum value from the 5 years.

\subsection{Primary predators of Puerto Rican parrots}

The Puerto Rican parrot is vulnerable to predation by multiple avian and mammalian species. Raptor predation is a major source of mortality for Puerto Rican parrots. Red-tailed hawks (Buteo jamaicensis) are the only year-round resident raptors in Puerto Rico consistently capable of taking Puerto Rican parrots (Snyder et al., 1987; Lindsey, 1992; Lindsey et al., 1994), although peregrine falcons (Falco peregrinus) occasionally winter in the vicinity of the wild parrot population and could pose a threat (Snyder et al., 1987). Protection from raptors would primarily entail year-round vigilance and opportunistic removal of red-tailed hawks near wild populations, and the dispersal of peregrine falcons from the parrot population area(s) during winter, if needed. Greatest effort would be required post-fledging and after releases of captive birds. Another natural avian enemy of the Puerto Rican parrot is the pearlyeyed thrasher (Margarops fuscatus), which usurps and predates the nests of the parrots (Snyder et al., 1987; Lindsey, 1992; Lindsey, 1994). This problem has been largely attenuated by providing nest boxes for the thrashers in the vicinities of parrot nests. Even so, thrashers regularly still threaten parrot nests and require removal. Besides these occasional removals, Puerto Rican parrot protection could include the oiling of thrasher eggs in the nest boxes. This method would keep the thrashers in their nests and defending entry into their territory from other thrashers, but their reproduction in the nest boxes would be unsuccessful, and they would not artificially benefit from use of nest boxes (e.g. Christens and Blokpoel, 1991; Cummings et al., 1997).

Several invasive mammal species also are potential threats to the parrots. The black or roof rat (Rattus rattus) is an exotic species introduced to Puerto Rico centuries ago. They are arboreal and terrestrial and threaten parrot nesting either through direct predation on eggs or young, or through harassment so that successful nesting cannot take place (Snyder et al., 1987; Lindsey, 1992). Rodriguez-Vidal (1959) considered rats to be the most important problem faced by nesting Puerto Rican parrots, but later some felt their threat, while real, might be less than first thought (Snyder et al., 1987). Recent data on rat populations (University of California-Davis, unpublished data) and parrot nest failures (US Fish and Wildlife Service and Caribbean National Forest, unpublished data) indicate that the original perception of rats as a major threat probably 
was correct. The feral cat (Felis catus) is another exotic species that has been documented as a Puerto Rican parrot predator (Rodriguez-Vidal, 1959; Snyder et al., 1987). Feral cats could be removed by a number of methods (Hygnstrom et al., 1994), especially during nesting and fledging. Recent efforts at indexing populations of potential mammalian parrot predators in the CNF have indicated high numbers of cats in the forest (University of California-Davis, unpublished data). The introduced Indian mongoose (Herpestes auropunctatus) is a voracious predator that was also found to be plentiful in University of California-Davis, unpublished data). Fledgling Puerto Rican parrots, or any others coming into contact with the ground are at risk for predation, and recent observations have documented that adult parrots will forage on the forest floor (University of California-Davis, unpublished data). While clear documentation of mongoose predation on Puerto Rican parrots is lacking, the methods for their management would be similar and carried out at the same time and in the same locations as for rats and cats. Rat, cat and mongoose management would be needed primarily during the nesting/fledging season and technologies for their removal are compatible for simultaneous application. Therefore, we considered management of the three mammal species as an inclusive group in terms of costs and practicality. An added benefit from mongoose removal beyond protecting Puerto Rican parrots is the reduction in risk of rabies transmission, which occurs in high prevalence in Puerto Rican mongoose populations (Velez-Valentin, 1998), and there have been recent mongoose attacks on humans in the CNF (Cano, unpublished data).

\subsection{Predator management costs}

A valid analysis of the benefits-costs for predator management requires a realistic assessment of the costs for predator management. The US Department of Agriculture/Wildlife Services (USDA/WS) is the only federal agency with a mandate to resolve human/wildlife conflicts. The work carried out by USDA/WS is specified by contracts, which are standardized in their devel- opment. USDA/WS currently has a variety of contracts in place on Puerto Rico for wild animal capture and removal. These existing contracts require similar levels of labor and resources as would be required for the removal of parrot predators. Thus, the costs for labor and materials were already well-defined and available for our use as a basis for predator management costs in Puerto Rican parrot protection. We considered the costs separately for managing predators associated with the current wild population in the CNF and the proposed site for the second population. If the duties of the biologist at the RA site were to be shared with parrot management duties, then costs would be similar to the CNF site. Without cost sharing, contract prices for predator management would be higher.

\subsection{Benefit-cost analysis (BCA)}

The potential Pareto improvements (e.g. Peterson and Randall, 1984) were derived for each aspect of predator control in each area. If a management program has positive net benefits, then Pareto improvements are possible (Boardman et al., 1996). A matrix of simulated scenarios was defined for each parrot population site whereby 1 , 2, 3, 4, 5 and 10 Puerto Rican parrots were assumed to be saved from each depredating species, and also for all predator species combined. Benefit-cost ratios (BCRs) for predator management were derived for the control scenarios through the monetary value of simulated numbers of parrots saved by the predator management. From this matrix, the parrots preserved through predator management that otherwise would not exist determined the economic impact on Puerto Rican parrots. The number of parrots preserved for the economic benefits of control to exceed its costs was identified.

The production of each parrot implies a per parrot value measured by the total annual budget at each location divided by the number of parrots produced at that location. This production cost or the amount of money expended to produce a parrot reflects the value of that parrot in dollars invested in individual production. Avoided loss of an individual parrot produced is seen as a benefit. 
In other words, if predation management prevents the loss of one parrot, then the benefit of that management effort is the dollar value of the parrot saved versus the costs of the effort. The costs of the predation management are broken down taxonomically, since methods, and therefore, costs are not the same for all species. The equation to calculate BCRs can be written as:

$$
\begin{aligned}
\mathrm{BCR} & =\frac{\text { Benefits }}{\text { Costs }} \\
& =\frac{\$ \text { value of parrot saved }}{\$ \text { cost of predation management }}
\end{aligned}
$$

In addition to calculating the BCR's, the net benefits by the number of parrots saved was also calculated. In order for protection efforts to be justified, the net benefits must be greater than zero. Net benefits are calculated by the equation,

$\mathrm{NB}_{\mathrm{i}}=\left(\mathrm{V}_{\mathrm{j}} \mathrm{N}\right)-\mathrm{C}_{\mathrm{s}}$,

where, $\mathrm{NB}_{\mathrm{i}}$ is the net benefit of a parrot saved at site i (i, Caribbean National Forest, Rio Abajo), $V_{j}$ is the value of a parrot ( $\mathrm{j}$, minimum or median), $\mathrm{N}$ represents the number of parrots saved, and $\mathrm{C}_{\mathrm{s}}$ denotes the cost of predation management for species s (s, red-tailed hawk, pearly-eyed thrasher, $\mathrm{rat} / \mathrm{cat} / \mathrm{mongoose}$ ). Minimum and median parrot values were used to calculate net benefits to allow for a range of conservative estimates accruing to predation management. This process is iterated for each site, predation species and number of parrots.

\section{Results}

\subsection{Puerto Rican parrot monetary values}

The number of healthy fledgling Puerto Rican parrots produced each year from each population, and their associated management budgets are given in Table 1. Budgeting figures for the Luquillo aviary could not be located for 1997 1999, and parrot values for those years were calculated based only on the figures from the RA aviary and the CNF wild population. The median value for the production of fledgling Puerto Rican parrots from 1997 through 2001 was \$22 105, and the minimum value was $\$ 8602$, which was used in the conservative analyses.

\subsection{Predator management costs}

A biologist with USDA/WS already is in place and available to carry out predator management duties in the CNF in addition to participating in other parrot management efforts. Determination of predator management costs was based primarily on this salary and overhead according to the proportion of the time that the individual would be required for predator management duties. If a second population is established in the future in the RA area, it is not clear whether the biologist responsible there for predator management would have duties, and costs, shared with other environmental responsibilities. If so, and if the division of labor would be similar to the existing situation in the $\mathrm{CNF}$, then the predator management costs also would be similar, hence the lower limits for $\mathrm{RA}$ in Table 2 are the same as for the CNF. If duties and costs could not be shared at the RA (future) population site, then the predator management costs would be similar to the higher limits for RA in Table 2.

\subsection{Benefit-cost analysis}

The BCA was used to determine in monetary terms the net benefit of each parrot saved by predator management at each location, based on the gross benefits and costs given the management of certain damaging species. The BCA followed the framework outlined in Loomis and Walsh (1997), Boardman et al. (1996), Nas (1996), Zerbe and Dively (1994) and Loomis (1993). The BCA of the predator approach involves estimating the monetary value of the benefits measured in parrots saved by reduced predation versus the costs of each predation program.

Table 3 shows the BCRs for each location by predating species. This table calculates the BCRs as the number of parrots saved increases, and it is obvious from the table that as the number of parrots saved increases, so do the BCRs. The greatest BCRs are achieved for the existing wild population in the CNF. Even when using the 
Table 1

Annual expenditures for the production of Puerto Rican parrots at three populations, the number of healthy fledglings produced, and the resulting average cost per parrot

\begin{tabular}{|c|c|c|c|c|c|c|c|c|c|}
\hline \multirow[t]{2}{*}{ Year } & \multicolumn{2}{|c|}{ Wild population } & \multicolumn{2}{|c|}{ Luquillo aviary } & \multicolumn{2}{|c|}{ RA aviary } & \multicolumn{2}{|l|}{ Total } & \multirow[t]{2}{*}{ Cost per parrot } \\
\hline & Budget & \# Parrots & Budget & \# Parrots & Budget & \# Parrots & Budget & \# Parrots & \\
\hline 2001 & 300000 & 5 & 157000 & 57 & 300000 & 14 & 757000 & 76 & 9961 \\
\hline 2000 & 300000 & 7 & 157000 & 65 & 128262 & 16 & 757000 & 88 & 8602 \\
\hline 1999 & 300000 & 3 & & & 108000 & 13 & 408000 & 16 & 25500 \\
\hline 1998 & 300000 & 9 & & & 120000 & 10 & 420000 & 19 & 22105 \\
\hline 1997 & 300000 & 7 & & & 128000 & 5 & 428000 & 12 & 35667 \\
\hline
\end{tabular}

minimum monetary valuation for Puerto Rican parrots, the prevention of a single mortality due to predation within the existing wild population results in monetary benefits slightly exceeding the combined costs for management of all predator species $(B C R=1.01)$. If median parrot values are applied, then only one parrot saved every 2.6 years allows the combined predator management to be cost-effective. The lowest BCRs result at the proposed RA population site when using the minimum parrot value and assuming the highest predator management costs. Even so, the combined predator management for all species is costeffective if 1.8 parrots/year are saved from predation. Use of median parrot value allows predation management to be cost-effective if one parrot is saved every 1.4 years. If actual costs for the RA site are the same as for the CNF, then the BCRs improve correspondingly. As more parrots are saved at each site, the BCRs increase dramatically. The results in Table 3 show that protection at any level to save any number of parrots creates a situation in which the annual benefits exceed the costs if parrots are valued at their median production costs. The same is true when using minimal parrot values, except when minimal parrot values and maximal costs are applied to save only one parrot at the RA site.

Even at the lowest net benefit, predation management produces a positive net benefit for the CNF wild population of $\$ 13605$ or $\$ 102$ when median and minimal parrot values are applied, respectively (Table 4). These numbers reflect that predation management even at the lowest parrot value produces a net cost savings. The greatest net benefits (\$212 553) accrue from the preservation of ten parrots from the wild population using the median parrot value. Prevention of up to ten

Table 2

The primary predators of Puerto Rican parrots, the associated potential predator management methods, and the estimated cost for each method if applied to the existing wild population in the CNF, as well as to the RA area proposed for creation of a second wild population

\begin{tabular}{llll}
\hline Species & Damage reduction approach and timing & Site \\
\cline { 3 - 3 } & & CNF $^{\text {RA }}$ & $\$ 1500-2500$ \\
\hline Pearly-eyed thrasher & Oiling eggs during parrot nesting/fledging & $\$ 1500-7500$ \\
Rat/cat/mongoose & Removal around parrot nest sites during nesting/fledging & $\$ 2000-3000$ & $\$ 2000-8500$ \\
Red-tailed hawk & Year-round management & $\$ 3000-5000$ & $\$ 3000-8500$ \\
\hline
\end{tabular}

\footnotetext{
${ }^{\text {a }}$ The costs for the RA area would be the same as for the CNF if the biologist was involved in cost sharing by assisting in parrot management efforts in addition to predator management.
} 
Table 3

BCRs for application of predator management to each predator species, and all species combined in the CNF and at the proposed RA site for a second population

\begin{tabular}{|c|c|c|c|c|c|c|c|c|c|c|c|c|c|}
\hline \multirow[t]{3}{*}{ Site } & \multirow{3}{*}{$\begin{array}{l}\text { Damaging species } \\
\text { Parrot values }\end{array}$} & \multicolumn{12}{|c|}{ BCRs by number of parrots saved } \\
\hline & & \multicolumn{2}{|l|}{1} & \multicolumn{2}{|l|}{2} & \multicolumn{2}{|l|}{3} & \multicolumn{2}{|l|}{4} & \multicolumn{2}{|l|}{5} & \multicolumn{2}{|l|}{10} \\
\hline & & Min & Median & Min & Median & Min & Median & Min & Median & Min & Median & Min & Median \\
\hline \multirow[t]{4}{*}{$\mathrm{CNF}$} & Pearly-eyed thrasher & 4.30 & 11.05 & 8.60 & 22.11 & 12.90 & 33.16 & 17.20 & 44.21 & 21.51 & 55.26 & 43.01 & 110.53 \\
\hline & Rat/cat/mongoose & 3.44 & 8.84 & 6.88 & 17.68 & 10.32 & 26.53 & 13.76 & 35.37 & 17.20 & 44.21 & 34.41 & 88.42 \\
\hline & Red-tailed hawk & 2.15 & 5.53 & 4.30 & 11.05 & 6.45 & 16.58 & 8.60 & 22.11 & 10.75 & 27.63 & 21.51 & 55.26 \\
\hline & Species combined & 1.01 & 2.60 & 2.02 & 5.20 & 3.04 & 7.80 & 4.05 & 10.40 & 5.06 & 13.00 & 10.12 & 26.01 \\
\hline \multirow[t]{4}{*}{ RA } & Pearly-eyed thrasher & 1.91 & 4.91 & 3.82 & 9.82 & 5.73 & 14.74 & 7.65 & 19.65 & 9.56 & 24.56 & 19.12 & 49.12 \\
\hline & Rat/cat/mongoose & 1.64 & 4.21 & 3.28 & 8.42 & 4.92 & 12.63 & 6.55 & 16.84 & 8.19 & 21.05 & 16.39 & 42.11 \\
\hline & Red-tailed hawk & 1.50 & 3.84 & 2.99 & 7.69 & 4.49 & 11.53 & 5.98 & 15.38 & 7.48 & 19.22 & 14.96 & 38.44 \\
\hline & Species combined & 0.55 & 1.43 & 1.11 & 2.85 & 1.66 & 4.28 & 2.22 & 5.70 & 2.77 & 7.13 & 5.55 & 14.26 \\
\hline
\end{tabular}

BCRs were calculated assuming both minimum and median Puerto Rican parrot values and assuming one to five and ten parrots were saved through the management actions.

Table 4

Net benefits (cost savings) for application of predator management to each predator species, and all species combined in the CNF and at the proposed RA site for a second population

\begin{tabular}{|c|c|c|c|c|c|c|c|c|c|c|c|c|c|}
\hline \multirow[t]{3}{*}{ Site } & \multirow{3}{*}{$\begin{array}{l}\text { Damaging species } \\
\text { Parrot values }\end{array}$} & \multicolumn{12}{|c|}{ Cost savings by number of parrots saved } \\
\hline & & \multicolumn{2}{|l|}{1} & \multicolumn{2}{|l|}{2} & \multicolumn{2}{|l|}{3} & \multicolumn{2}{|l|}{4} & \multicolumn{2}{|l|}{5} & \multicolumn{2}{|l|}{10} \\
\hline & & Min & Median & Min & Median & Min & Median & Min & Median & Min & Median & Min & Median \\
\hline \multirow[t]{4}{*}{$\mathrm{CNF}$} & Pearly-eyed thrasher & 6602 & 20105 & 15205 & 42211 & 23807 & 64316 & 32409 & 86421 & 41011 & 108526 & 84023 & 219053 \\
\hline & Rat/cat/mongoose & 6102 & 19605 & 14705 & 41711 & 23307 & 63816 & 31909 & 85921 & 40511 & 108026 & 83523 & 218553 \\
\hline & Red-tailed hawk & 4602 & 18105 & 13205 & 40211 & 21807 & 62316 & 30409 & 84421 & 39011 & 106526 & 82023 & 217053 \\
\hline & Species combined & 102 & 13605 & 8705 & 35711 & 17307 & 57816 & 25909 & 79921 & 34511 & 102026 & 77523 & 212553 \\
\hline \multirow[t]{4}{*}{ RA } & Pearly-eyed thrasher & 4102 & 17605 & 12705 & 39711 & 21307 & 61816 & 29909 & 83921 & 38511 & 106026 & 81523 & 216553 \\
\hline & Rat/cat/mongoose & 3352 & 16855 & 11955 & 38961 & 20557 & 61066 & 29159 & 83171 & 37761 & 105276 & 80773 & 215803 \\
\hline & Red-tailed hawk & 2852 & 16355 & 11455 & 38461 & 20057 & 60566 & 28659 & 82671 & 37261 & 104776 & 80273 & 215303 \\
\hline & Species combined & $(6898)$ & 6605 & 1705 & 28711 & 10307 & 50816 & 18909 & 72921 & 27511 & 95026 & 70523 & 205553 \\
\hline
\end{tabular}

Net benefits were calculated assuming both minimum and median Puerto Rican parrot values and assuming one to five and ten parrots were saved through the management actions. 
parrot losses by predation is not an unprecedented concept, as that many have succumbed to redtailed hawk predation immediately after release of captive-bred birds (Rios, personal communication). Even the RA site when assuming higher costs and median parrot value produces a minimum net benefit of $\$ 6605$ (Table 4). Overall, predation management creates a situation in which the benefits exceed the costs, justifying management costs at all parrot values and all sites.

\section{Discussion}

Determination of the economics of predator control has been valuable to formulation of management strategies elsewhere (e.g. Engeman et al., 2002). The Puerto Rican parrot is an extremely rare animal, and we have demonstrated that the combined costs for managing multiple predatory threats is more than offset by saving a single parrot in the existing wild populations. The BCRs and net benefits from predator management inflate as one proceeds from extremely conservative valuation for parrots to median production values. One could argue that the maximal parrot production value averaged across populations from Table 1 (\$35667) is appropriate to apply, because that level of expenditure has already been demonstrated. For the sake of this argument, we used the maximum parrot value and calculated the BCR when predator management simultaneously directed at each of the predator species in the CNF results in one parrot saved. We found that this level of predator management is cost-effective if only one parrot is preserved every 4.2 years. We legitimately can carry this line of reasoning a further step to observe in Table 1 that the perparrot produced expenditure in 1999 for the wild population was $\$ 100000$. Use of this empirical valuation for Puerto Rican parrots shows that the combined application of all forms of predator management would be cost-effective if only one parrot is preserved every 11.8 years. The primary point is that one could safely presume that a single parrot protected from predators could offset a number of years of management expenses for all of the predator species. The same holds true if a second population is established at the RA site. We approached this scenario in a more conservative fashion by assuming that predator management costs would be higher, without assuming that parrot management expenditures, and therefore, parrot valuation, would probably increase to a greater extent.

It is possible that other species may eventually be identified as posing sufficiently meaningful predatory threats to the parrots that their management might be warranted. This is especially true for the RA area where Puerto Rican parrots do not yet exist in the wild and consequently predation data are not available. For example, the Puerto Rican boa (Epicrates inornatus) has been observed to predate Puerto Rican parrots (Snyder et al., 1987; Lindsey, 1992). The karst habitat in the RA area is likely more suitable for Puerto Rican boas than the CNF, possibly resulting in greater snake numbers there. However, the boas are a protected species, and would require different approaches than invasive species or even abundant native species. Research might well show that they can be captured using some of the (nonlethal) methods applied for brown tree snake control on Guam (Engeman and Vice, 2001) and translocated away from Puerto Rican parrot nesting areas. Additional economic analyses of the merits of protecting Puerto Rican parrots from other predator species might be warranted if evidence is gathered to indicate they present a consequential risk. Given our current results, it is likely that the methods for managing these additional predators would also be highly cost-effective.

The conservatism in our economic analyses is even greater if one considers that estimated replacement costs do not compensate for the immediate loss of biotic potential within demes, nor do those replacement costs account for the more consequential, irretrievable loss of pooled genetic variation through subsequent generations. Unfortunately, it is impossible to ascribe monetary value to the loss of random mating events and the infinite possibilities for genetic recombination associated with them. We also do not attempt to define an existence value to describe the value that a person might enjoy just knowing that Puerto Rican parrots exist in the wild (e.g. Krutilla and 
Fisher, 1985). Examination of the economic aspects of the potential returns on predator management as a conservation method for Puerto Rican parrots indicates that resources allocated for this purpose would be efficiently expended.

\section{References}

Boardman, A.E., Greenberg, D.H., Vining, A.R., Weimer, D.L., 1996. Cost-Benefit Analysis: Concepts and Practice. Prentice Hall, Upper Saddle River, NJ, pp. 187-205.

Bodenchuk, M.J., Mason, J.R., Pitt, W.C., 2002. Economics of predation management in relation to agriculture, wildlife, and human health and safety. In: Clark, L. (Ed.), Proceedings of the First International Symposium on the Economics of Wildlife Damage Management. Colorado State University, Fort Collins, CO, pp. 80-90.

Christens, E., Blokpoel, H., 1991. Operational spraying of white mineral oil to prevent hatching of gull eggs. Wildlife Society Bulletin 19, 423-430.

Cummings, J.L., Pitzler, M.E., Pochop, P.A., Krupa, H.W., Pugh, T.L., May, J.A., 1997. Field evaluation of white mineral oil to reduce hatching in Canada goose eggs. In: Lee, C.D., Hygnstrom, S.E. (Eds.), Proceedings of the 13th Great Plains Wildlife Damage Control Workshop. Kansas State University Agricultural Experiment Station and Cooperative Extension Service, Manhattan, KS, pp. 67-72.

Danielle, A., Murray, N.D., 1986. Effects of inbreeding in the budgerigar (Melopsitttacus undulatus). Zoological Biology $5,233-238$.

Derrickson, S.R., Snyder, N.F.R., 1991. Potentials and limits of captive breeding in parrot conservation. In: Beissinger, S.R., Snyder, N.F.R. (Eds.), New World Parrots in Crisis: Solutions from Conservation Biology. Smithsonian Institution Press, Washington, DC, pp. 133-163.

Engeman, R.M., Vice, D.S., 2001. Objectives and integrated approaches for the control of brown tree snakes. Integrated Pest Management Reviews 6, 59-76.

Engeman, R.M., Shwiff, S.A., Constantin, B., Stahl, M., Smith, H.T., 2002. An economic analysis of predator removal approaches for protecting marine turtle nests at Hobe Sound National Wildlife Refuge. Ecological Economics 42, 469-478.

Engeman, R.M., Shwiff, S.A., Smith, H.T., Constantin, B. Monetary valuation methods for economic analysis of the benefit-costs of protecting rare wildlife species from predators. Integrated Pest Management Reviews, in press.

Franklin, I.R., 1980. Evolutionary change in small populations. In: Soule, M.E., Wilcox, B.A. (Eds.), Conservation Biology: an Evolutionary-Ecological Perspective. Sinauer, Sunderland, MA, pp. 135-150.

Hecht, A., Nickerson, P.R., 1999. The need for predator management in conservation of some vulnerable species. Endangered Species Update 16, 114-118.
Hygnstrom, S.E., Timm, R.M., Larson, G.E., 1994. Prevention and Control of Wildlife Damage, vol. I. Univ. Neb. Coop. Exten, US Dept. Ag., Great Plains Ag Council, Washington, DC.

Krutilla, J.V., Fisher, A.C., 1985. The economics of natural environments: studies in the valuation of commodity and amenity resources. Resources for the Future, Washington, DC, pp. 39-78.

Lacey, R.C., 1987. Loss of genetic diversity from managed populations: interacting effects of drift mutation, immigration, selection, and population subdivision. Conservation Biology 1, 143-158.

Lindsey, G.D., 1992. Nest guarding from observation blinds: strategy for improving Puerto Rican parrot nest success. Journal of Field Ornithology 63, 466-472.

Lindsey, G.D., Arendt, W.J., Kalina, J., 1994. Survival and causes of mortality in juvenile Puerto Rican parrots. Journal of Field Ornithology 65, 76-82.

Loomis, J.B., 1993. Integrated Public Lands Management: Principles and Applications to National Forests, Parks, Wildlife Refuges and BLM Lands. Columbia University Press, New York, pp. 116-170.

Loomis, J.B., Walsh, R.G., 1997. Recreation Economic Decisions: Comparing Benefits and Costs, second ed. Venture Publishing, Inc. State College, Pennsylvania, pp. 369-410.

Nas, T.F., 1996. Cost-Benefit Analysis: Theory and Application. Sage Publications, California, pp. 57-66.

Peterson, G.L., Randall, A., 1984. Valuation of Wildland Resource Benefits. Westview Press, Boulder, CO; London, UK, p. 258.

Reynolds, J.C., Tapper, S.C., 1996. Control of mammalian predators in game management and conservation. Mammal Review 26, 127-156.

Rodriguez-Vidal, J.A. 1959. Puerto Rican parrot study. Monograph, Department of Agriculture of Commonwealth of Puerto Rico. No. 1.

Scott, M.E., 1988. The impact of infection and disease on animal populations: implications for conservation biology. Conservation Biology 2, 40-56.

Snyder, N.F.R., Wiley, J.W., Kepler, C.B., 1987. The parrots of Luquillo: natural history and conservation of the Puerto Rican parrot. West. Found. Vetebr. Zool. Los Angeles, CA, p. 384.

US Fish and Wildlife Service, 1982. Puerto Rican Parrot Recovery Plan. U.S.F.W.S. Region 4, Atlanta, GA, p. 44.

US Fish and Wildlife Service, 1999. Technical/Agency Draft Revised Recovery Plan for the Puerto Rican Parrot (Amazona vittata). U.S.F.W.S. Region 4, Atlanta, GA, p. 77.

Velez-Valentin, J., 1998. Presencia de anticuerpos antirabicos y diagnostico de la rabia en mangostas capturadas en el Bosque Nacional del Caribe (El Yunque). MS thesis, University of Puerto Rico.

Vilella, F.J., Garcia, E.R., 1995. Post-hurricane management of the Puerto Rican parrot. In: Bissonette, J.A., Krausman, P.R. (Eds.), Integrating People and Wildlife for a sustainable Future. Proceedings of the First International Wildlife 
Management Congress. The Wildlife society, Bethesda, MD, pp. 618-621.

Warner, R.E., 1968. The role of introduced diseases in the extinction of the endemic Hawaiian avifauna. Condor 70, $101-120$.

Wiley, K.A., Snyder, N.F.R., Gnam, R.S., 1991. Reintroduction as a conservation strategy for parrots. In: Beissinger,
S.R., Snyder, N.F.R. (Eds.), New World Parrots in Crisis: Solutions from Conservation Biology. Smithsonian Institution Press, Washington, DC, pp. 165-200.

Zerbe, R.O., Dively, D.D., 1994. Benefit-Cost Analysis: In Theory and Practice. HarperCollins College Publishers, New York, NY, pp. 369-394. 